\title{
Removal of Heavy Metals from Liquid Wastes
}

\author{
Amany Ahmed Mahmoud Ibrahim Mahmoud ${ }^{1}$, Ehssan M. Nassef ${ }^{2}$, Yehia A. El-taweel ${ }^{1}$ \\ ${ }^{1}$ Department of Chemical Engineering, Faculty of Engineering, Alexandria University, Alexandria, Egypt \\ ${ }^{2}$ Department of Petrochemical Chemical, Faculty of Engineering, Pharos University, Alexandria, Egypt
}

Email address:

mony_6002000@yahoo.com (A. A. M. I. Mahmoud)

\section{To cite this article:}

Amany Ahmed Mahmoud Ibrahim Mahmoud, Ehssan M. Nassef, Yehia A. El-taweel. Removal of Heavy Metals from Liquid Wastes. American Journal of Chemical Engineering. Vol. 4, No. 4, 2016, pp. 87-91. doi: 10.11648/j.ajche.20160404.12

Received: July 1, 2016; Accepted: July 9, 2016; Published: July 28, 2016

\begin{abstract}
The present study is a study on the removal of heavy metal ion (Cu (II)) from copper ions solution by high molecular weight compound inorganic nature. This compound is modified clay (activated bentonite) which is used in oil well drilling, and obtained from local company. The experimental results with the modified clay show that it is an adsorption reaction that follows Langmuir isotherm model. The maximum removal of copper ions was obtained at low copper ion initial concentration, high adsorbent dosage, low temperature, and high agitation speed. It is clear from the results obtained that the compound within the experimental range investigated cannot be considered as a method for the removal of waste stream within the experimental range investigated as the residual concentration is higher than the limits which are allowed by the environmental limits which are allowed by the low which is $5 \mathrm{ppm}$. These results may be due to the high initial copper concentration used in this work and low dosage of the compound.
\end{abstract}

Keywords: Waste Water, $\mathrm{Cu}$ (II), $\mathrm{CuSO}_{4}$, Modified Clay (Activated Bentonite), Adsorption

\section{Introduction}

Heavy metals are elements having atomic weights between 63.5 and 200.6, and a specific gravity greater than 5.0 [1]. With the rapid development of industries such as metal plating facilities, mining operations, fertilizer industries, tanneries, batteries, paper industries and pesticides, etc., heavy metals in wastewaters are directly or indirectly discharged into the environment increasingly, especially in developing countries. Unlike organic contaminants, heavy metals are not biodegradable and tend to accumulate in living organisms and many heavy metal ions are known to be toxic or carcinogenic. Toxic heavy metals of particular concern in treatment of industrial wastewaters include zinc, copper, nickel, mercury, cadmium, lead and chromium. Copper does essential work in animal metabolism. But the excessive ingestion of copper brings about serious toxicological concerns, such as vomiting, cramps, convulsions, or even death. Many methods that are being used to remove heavy metal ions include chemical precipitation, ion-exchange, adsorption, membrane filtration, electrochemical treatment technologies, etc. The objective of this study is to remove one hazard heavy metal which is Copper (II).

The removal technique done in this work was adsorption of Copper (II) on the surface of high molecular weight compound was studied. This was sodium carbonate activated bentonite. The main objective of this work is to examine the different parameters which affect on the residual concentration and the percentage removal of the consumed ion. These parameters are initial concentration of metal ion, adsorbent dosage, stirring rate and temperature.

\section{Material and Methods}

\subsection{Chemicals}

Experimental solutions of the desired concentrations were obtained by successive dilution with distilled water. Copper Sulphate $\mathrm{CuSO}_{4} .5 \mathrm{H}_{2} \mathrm{O}$ was used as a source of Copper salt in the adsorption experiments. A stock solution of Copper sulfates solution was prepared by using an analytical grade chemicals and dissolving them in distilled water. 


\subsection{Physicochemical Characterization of Adsorbent}

The modified clay used in this work was obtained from Egypt company for oily clay. Activated bentonite brown in color, it was characterized by $\mathrm{x}$-ray florescence (XRF) and chemical analysis the analysis was made in Central Metallurgical Research Institute. The chemical composition of the tested samples is given in table (1).

Table 1. Chemical Characterization of Bentonite.

\begin{tabular}{ll}
\hline Oxides & Wt.\% \\
\hline $\mathrm{SiO}_{2}$ & 55.12 \\
$\mathrm{Al}_{2} \mathrm{O}_{3}$ & 16.14 \\
$\mathrm{Fe}_{2} \mathrm{O}_{3}$ & 8.25 \\
$\mathrm{CaO}$ & 1.17 \\
$\mathrm{TiO}_{2}$ & 1.18 \\
$\mathrm{MgO}$ & 2.86 \\
$\mathrm{~K}_{2} \mathrm{O}$ & 1.05 \\
$\mathrm{Na}_{2} \mathrm{O}$ & 1.41 \\
L.O.I & 12.35 \\
\hline
\end{tabular}

\subsection{Morphology Study of Modified Clay}

A scan electron microscope with different magnification was done on dry base for a sample of clay to specify the morphological features of bentonite as shown in figure (1). This bentonite has low alumina content (16.14\%) and contains high silica contents (55.12\%) [2]. Bentonite shows higher distribution of alkali oxides. There is general agreement between the current obtained values for both major oxide contents and with the calculated values and recorded results previously obtained for Egyptian kaolin and bentonite [3-5].

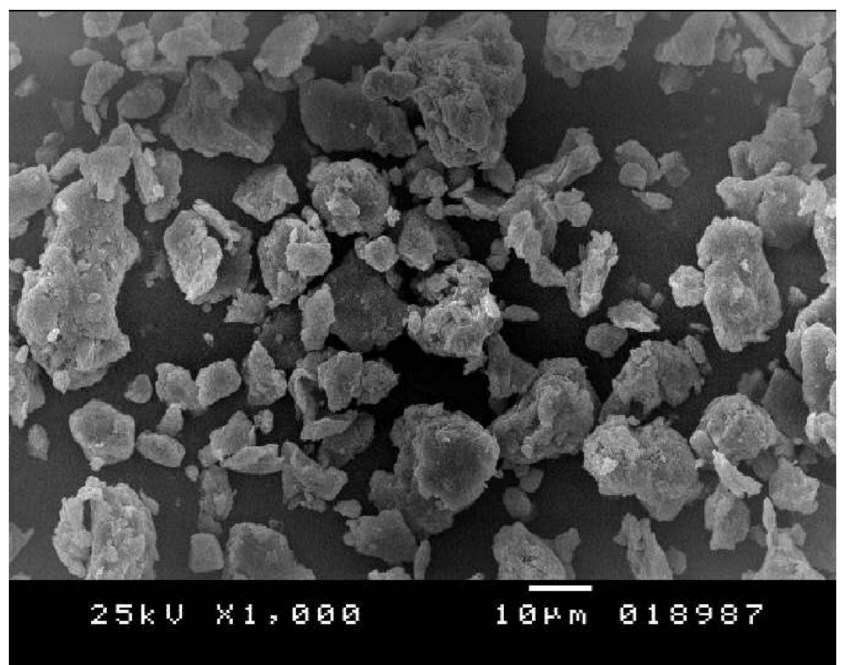

Figure 1. Scanning Electron Microscope (SEM) of dry bentonite.

\subsection{Adsorption Procedures}

The required weight of an adsorbent (bentonite) was prepared. Then the stock solution containing $1000 \mathrm{mg}$ of metal ion solutions $\left(\mathrm{CuSO}_{4} .5 \mathrm{H}_{2} \mathrm{O}\right)$ were prepared from their stock solutions and then were mixed with different weight of adsorbents. The solutions were then agitated at room temperature or at other experimental temperature, after mixing for a time specified according to experimental conditions the samples were filtered using Whitman filter paper and the filtrates were analyzed using buret. The experiments were conducted using an orbital shaker for a known period of time. Adsorption experiments were carried out in flasks of $100 \mathrm{~mL}$.

The percentage of removal of the heavy metal ions $(\% \mathrm{R})$ in solution was calculated using Equation (1):

$\mathrm{N}_{\text {EDTA }} \mathrm{V}_{\text {EDTA }}=\mathrm{N}_{\mathrm{CU} \text { (ii) }} \mathrm{V}_{\mathrm{CU} \text { (ii) }}=$ eq. $\mathrm{Cu}$ (II), if $\mathrm{V}$ is given in $\mathrm{L}$.

$=\mathrm{m}$ eq. $\mathrm{Cu}$ (II), if $\mathrm{V}$ is given in $\mathrm{mL}$.

The mass of $\mathrm{Cu}$ equals (eq. $\mathrm{Cu}$ (II)) $\mathrm{x}$ (equivalent mass of $\mathrm{Cu}$ (II)), and

$$
\% \mathrm{Cu}=\frac{\operatorname{mass} C u(I I)}{\operatorname{mass} C u(I I) \text { salt }} \times 100
$$

The concentration of $\mathrm{Cu}$ (II) in aqueous solutions before and after adsorption were determined as the following:

$$
\begin{aligned}
\text { Original } \mathrm{Cu}^{+2} & =\frac{\text { initial volume }}{100} \times 63.5 \\
\text { Residual } \mathrm{Cu}^{+2} & =\frac{\text { remained volume }}{100} \times 63.5
\end{aligned}
$$

Adsorbed $\mathrm{Cu}^{+2}\left(\mathrm{q}_{\mathrm{t}}\right)=\left(\right.$ original $\mathrm{Cu}^{+2}-$ residual $\left.\mathrm{Cu}^{+2}\right) \times 10^{4}$

( $\mathrm{mg} \mathrm{Cu} \mathrm{Cu}^{+2}$ adsorbed/g adsorbent)

$$
\% \text { removal }=\frac{C_{o}-C_{t}}{C_{o}} \times 100
$$

Where,

$\mathrm{C}_{0}=$ Initial concentration of heavy metal $(\mathrm{mg} / \mathrm{L})$.

$\mathrm{C}_{\mathrm{t}}=$ Heavy metals concentrations $(\mathrm{mg} / \mathrm{L})$ at a given time $\mathrm{t}$.

The results were plotted versus $t$.

\section{Results and Discussion}

\subsection{Effect of Initial Metal Ion Concentration}

Figures (2), (3) indicate the effect of initial concentration and of the $\mathrm{Cu}$ (II) ions on the residual concentration and percentage removal respectively. It was found that as the initial concentration of $\mathrm{Cu}$ (II) increases the residual concentration increases and the percentage removal decreases. From figures it is evident that at high concentration, the available sites of adsorption become fewer. This behavior is connected with the competitive diffusion process of the $\mathrm{Cu}$ (II) ions through the micro-channel and pores in the modified clay. That adsorption of metallic ions will lock the inlet of channel on the surface and prevent the metal ions from passing deeply inside the modified clay. The adsorption occurs on the surface only. Similar results in previous studies using natural zeolite [6] and olive cake [7], in addition to what have been found by karthikeyan et al. [8] confirm this point of view. 


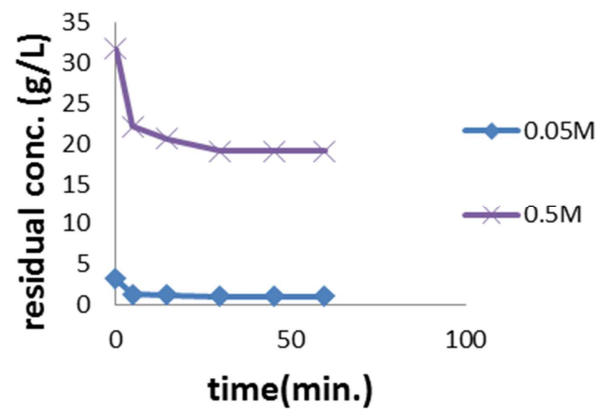

$(\mathrm{pH}=4.6$, agitation speed $=150 \mathrm{rpm}$, modified clay mass $=0.1 \mathrm{~g}$, and Temp. $=25^{\circ} \mathrm{C}$ ).

Figure 2. Effect of initial metal ion concentration on the residual concentration of $\mathrm{Cu}$ (II).

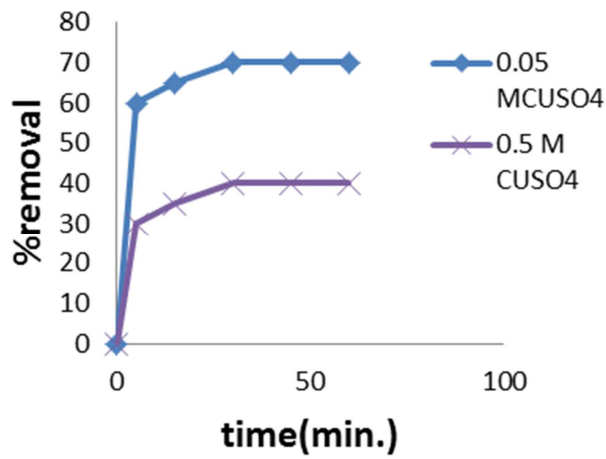

$(\mathrm{pH}=4.6$, agitation speed $=150 \mathrm{rpm}$, modified clay mass $=0.1 \mathrm{~g}$, and Temp $\left.=25^{\circ} \mathrm{C}\right)$.

Figure 3. Effect of initial metal ion concentration on the \% removal of $\mathrm{Cu}$ (II).

From figures ((2), (3)) the adsorption of modified clay reached the equilibrium after 30 minutes.

\subsection{Effect of Modified Clay Dosage}

The effluence of modified clay masses on the percentage removal of $\mathrm{Cu}$ (II) is shown in figure (4). This figure showed that as the amount of modified clay increases the percentage removal of $\mathrm{Cu}$ (II) increases. This is may be due to those higher amounts of modified clay means availability of a larger surface area or a larger number for adsorption sites [9] and therefore, higher capacity for adsorption.

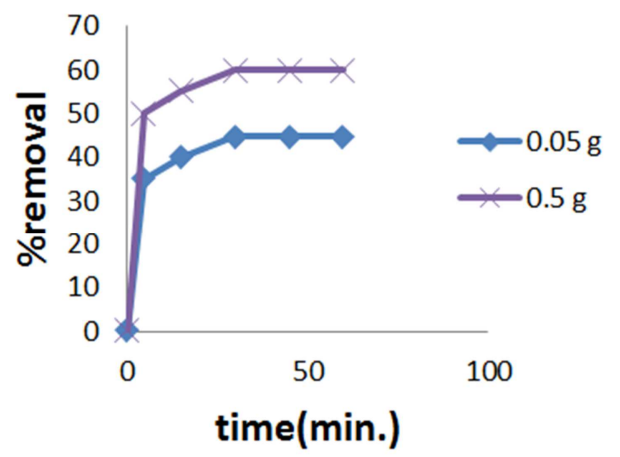

$\left(\mathrm{pH}=4.6\right.$, agitation speed $=150 \mathrm{rpm}, 0.25 \mathrm{M} \mathrm{CuSO}_{4}$, and Temp. $\left.=25^{\circ} \mathrm{C}\right)$.

Figure 4. Effect of modified clay dosage on the percentage removal of $\mathrm{Cu}$ (II).

\subsection{Effect of Shaking Speed (r.p.m)}

Figure (5) indicates the effect of shaking speed on the percentage removal of $\mathrm{Cu}$ (II). It was found that as the shaking speed increases the percentage removal increases. The increase in shaking speed resulting to increase in metal ions percentage removal, which was due to the fact that, increase in stirring rate enhanced the metal ions diffusion to the surface of modified clay, and also caused reduction in the film boundary layer around the adsorbent [10], also the increase in efficiency was due to the increase in turbulence and, as a consequence, the decrease in the external mass transfer resistance thickness around the adsorbent particles with increase in mixing speed [11].

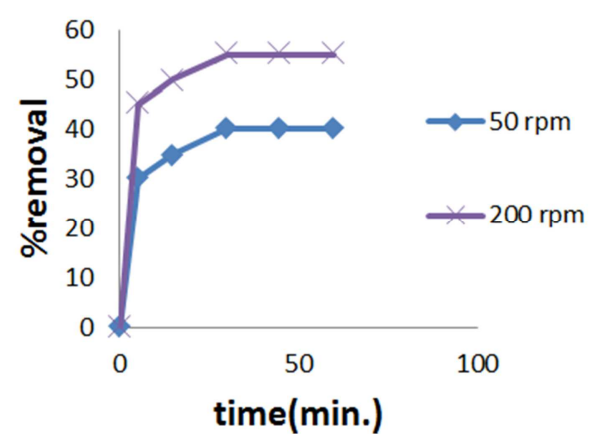

$\left(\mathrm{pH}=4.6\right.$, modified clay mass $=0.1 \mathrm{~g}, 0.25 \mathrm{M} \mathrm{CuSO}_{4}$, and Temp. $\left.=25^{\circ} \mathrm{C}\right)$.

Figure 5. Effect of r.p.m on the percentage removal of $\mathrm{Cu}$ (II).

\subsection{Effect of Temperature}

Figure (6) indicates the effect of temperature on the percentage removal on $\mathrm{Cu}$ (II). It was found that as the temperature increases the percentage removal decreases. This was because with increasing temperature, the attractive forces between the adsorbent surface and metal ions are weakened and the desorption decreases. At high temperature, the thickness of the boundary layer decreases, due to the increased tendency of the metal ion to escape from the biomass surface to the solution phase, which results in a decrease in adsorption as temperature increases (Aksu and Kutsal, 1991), As a whole, it is clearly seen that as the temperature increases the loading capacity for the same initial adsorbent concentration decreases. This means that the rate of desorption was more significant than the rate of adsorption, which implies that adsorption in this case is an exothermic reaction [12].

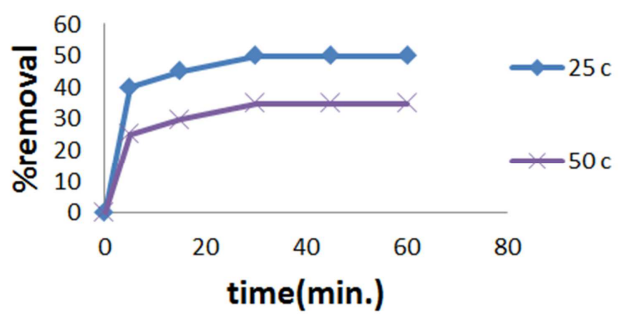

( $\mathrm{pH}=4.6$, modified clay mass $=0.1 \mathrm{~g}, 0.25 \mathrm{M} \mathrm{CuSO}_{4}$, and agitation speed $=150 \mathrm{rpm}$ ).

Figure 6. Effect of temperature on the percentage removal of Cu (II). 


\subsection{Adsorption Isotherm Studies}

The analysis of isotherm data which were showed by fitting models that can be used for design purposes. Adsorption isotherm study was carried out on two isotherm models: Langmuir, and Freundlich isotherm models. The applicability of the isotherm models to the adsorption study done was compared by judging the correlation coefficient, $\mathrm{R}^{2}$ values.

\subsubsection{Langmuir Isotherm Model}

Langmuir's isotherm model suggests that the uptake occurs on homogeneous surface by monolayer sorption without interaction between adsorbed ions. The linear form of Langmuir isotherm equation is represented by the following equation $[13,14]$ :

$$
\frac{c_{e}}{Q_{e}}=\frac{1}{Q^{0} b}+\frac{1}{Q^{0}} C_{e}
$$

Where $\mathrm{Q}^{\circ}$ is the maximum $\mathrm{Cu}^{++}$ions uptake per unit mass of polymer $(\mathrm{mg} / \mathrm{g})$ related to adsorption capacity and $\mathrm{b}$ is Langmuir constant $(\mathrm{L} / \mathrm{mol})$ related to energy of sorption. Therefore, a plot of (Ce/qe) versus $\mathrm{Ce}$, gives straight line of slope $1 / Q^{\circ}$ and intercept $1 /\left(Q^{\circ} b\right)$. Figure (7) shows the experimental data that were fitted by the linear form of Langmuir model, (Ce/qe) versus $\mathrm{Ce}$. The values of $Q^{\circ}$ and $b$ were evaluated from the slope and intercept respectively. These values of $Q^{\circ}$ and $\mathrm{b}$ are listed in Table (2) with their uncertainty and their determination coefficient, $\mathrm{R}^{2}$. The results obtained from the Langmuir model for the removal of $\mathrm{Cu}^{++}$onto modified clay in table (2) which showed strong positive evidence on the adsorption of $\mathrm{Cu}^{++}$onto modified clay follows the Langmuir isotherm. The applicability of linear forms of Langmuir model modified clay was proved by the high correlation coefficients $R^{2}>0.99$. This suggests that the Langmuir isotherm provides a good model of the sorption system.

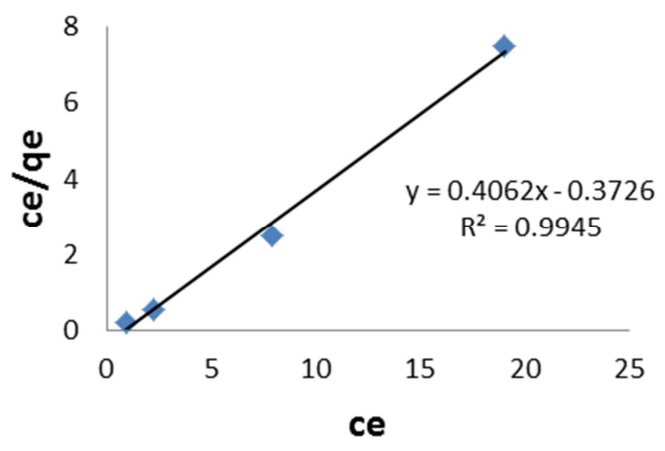

Figure 7. Langmuir isotherm model.

\subsubsection{Freundlich Isotherm Model}

Freundlich isotherm describes the adsorption equation for non-ideal adsorption that involves heterogeneous adsorption. This empirical isotherm is expressed by the following equation $[13,15]$ :

$$
Q_{e}=K_{F} C_{e}^{1 / n}
$$

The equation is conveniently used in the linear form by taking the logarithm of both sides as:

$$
\log Q_{e}=\log K_{F}+\frac{1}{n} \log C_{e}
$$

Freundlich constants, $K_{F}$ and $1 / \mathrm{n}$, are related to adsorption capacity and intensity of adsorption, respectively. The value of $\mathrm{n}$ and $K_{F}$ can be calculated from the slope and intercept of the plot of $\log \mathrm{q}_{\mathrm{e}}$ versus $\log C_{e}$ derived from Eqn. (8). The magnitude of the exponent $1 / \mathrm{n}$ gives an indication of the favorability of adsorption, where values in the range of 2-10 represents good adsorption 1-2 gives moderate adsorption and less than 1 means that the adsorption has poor characteristics [16]. The applicability of the Freundlich sorption isotherm was also analyzed, using the same set of experimental data, by plotting $\log \left(\mathrm{Q}_{\mathrm{e}}\right)$ versus $\log \left(C_{e}\right)$. The data obtained from linear Freundlich isotherm plot for the adsorption of the $\mathrm{Cu}^{++}$onto modified clay. The correlation coefficients reported in figure (8).

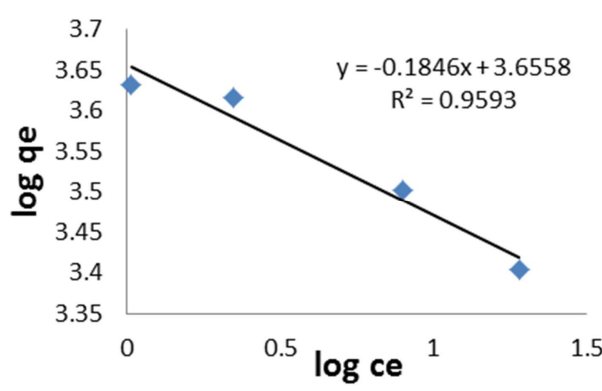

Figure 8. Freundlich isotherm model.

The equilibrium experimental results of adsorbed modified clay at various initial concentrations of $\mathrm{CuSO}_{4}$ were compared by using the adsorption isotherm equations, namely Langmuir, and Freundlich models. The temperature was constant throughout the experiments at $25^{\circ} \mathrm{C}$. The experimental results were fitted to Langmuir and Freundlich models were done by linear regression using the statistical analysis package Excel.

Figure (7), and Figure (8) show the fitted equilibrium data of Langmuir, and Freundlich respectively.

For model comparison accordingly to $\mathrm{R}^{2}$ which are shown in table (2) we concluded that Langmuir isotherm is the best model to fit the data.

Table 2. Values of $Q^{\circ}, b$, and $R^{2}$ for Langmuir and freundlich isotherm models.

\begin{tabular}{lll}
\hline Model & Langmuir & Freundlich \\
\hline $\mathrm{R}^{2}$ & 0.9945 & 0.9593 \\
$Q^{\circ}$ & 0.4062 & -0.1846 \\
$\mathrm{~B}$ & -0.3726 & 3.6558 \\
\hline
\end{tabular}

According to $\mathrm{R}^{2}$, the higher the value of $\mathrm{R}^{2}$ the better model, from table (2), we found out Freundlich model has the least $\mathrm{R}^{2}$ value $(0.9593)$ while the other model Langmuir isotherm model has the highest value of $R^{2}$ which is (0.9945). Therefore, Langmuir isotherm model is the best model to describe the $\mathrm{CuSO}_{4}$ adsorption system on modified clay. For freundlich model we found that $1 / \mathrm{n}=0.1846$, so that 
$\mathrm{n}=5.41711809$, therefore it lies in the interval 2-10 and applied good adsorption.

\section{Conclusions and Recommendations}

Modified clay remove $\mathrm{Cu}$ (II) from solutions by adsorption, it follows Langmuir isotherm model.

Maximum percentage removal takes place at low initial metal ion concentration, high shaking speed, low temperature, and high amount of adsorbent dosage.

The results show that the use of modified clay cannot be considered as a waste treatment method for the removal of copper from solution within the experimental range investigated.

The following recommendations may be considered for further studies: using low initial metal ion concentration, working at low temperature during the adsorption process, using high shaking speed (r.p.m), and using large amount of compound dosage.

\section{Acknowledgment}

Amany A. Mahmoud would like to earnestly express her gratitude to Eng. Khaled Elkady the sector head of the environmental section of the research and consulting sector at Comibassal International Controllers for his effort in supporting and allowing her to carry out this study.

\section{References}

[1] N. K., Srivastava, Majumder, and C. B.; "Novel biofiltration methods for the treatment of heavy metals from industrial wastewater", J. Hazard. Mater. 151, Issues 1-8, (2008).

[2] E., Naseef; "Thermodynamics and Kinetic Study of using modified clay as an adsorbent for the removal of $\mathrm{Zn}$ ions from waste water", Journal of American Science, Water Res. 9 (9), (2013).

[3] O., Abollino; "Adsorption of Heavy Metals on NaMontmorillonite Effect of $\mathrm{pH}$ and Organic Substances", Water Research, Volume 37, pp. 1619-1627, (2003).

[4] M. Rashed and M. Soltan, "Removal of Nutrients and Heavy Metals from Urban Wastewater Using Aeration Alum and Kaolin Ore", Proceeding EPCOWM, pp. 621-627, (2002).

[5] M.M. Wahba and A.M Zaghloul, "Adsorption Characteristics of Some Heavy Metals by Some Soil Minerals", Journal of Applied Sciences Research, Volume 3, pp. 421-426, (2007).

[6] M., Al-Anber, and Z., Al-Anber; "Utilization of natural zeolite as ion-exchange and sorbent material in the removal of iron", Desalination 255, pp. 70-81, (2008).
[7] Z., Al-Anber, and M., Al-Anber; "Thermodynamics and Kinetic Studies of Iron (III) Adsorption by Olive Cake in a Batch System”, pp. 108-115, (2008).

[8] G. Karthikeyan, N. M. Andal, and K. Anbalagan; "Adsorption studies of iron (III) on chitin”, J. Chem. Sci 117(6), pp. 663672, (2005).

[9] A. I., Zouboulis, K. A., Kydros, and K. A. Matis; "flotation of metal-loaded clay Anion Exchangers", water res. 29, (1995).

[10] E., Bernard, A., Jimoh and J.O., Odigure; "Heavy metals removal from industrial wastewater by activated carbon", research journal of chemical sciences, Volume 3(8), Issues 39, (2013).

[11] Z., Al-Qodah; "Biosorption of heavy metal ions from aqueous solutions by activated sludge", Desalination, 196, pp. 164176, (2006).

[12] A., Addagalla, A., Darwish, and N., Hilal; "Study of various parameters in the biosorption of heavy metals on activated sludge", World Applied Sciences Journal 5 (Special Issue for Environment), pp. 32-40, (2009).

[13] N, M., Agyei, C. A., Strydom, and J.H., Potgieter; "An investigation of phosphate ion adsorption from aqueous solution by fly ash and slag. Cem., and Concr", Res.,30(5), pp. 823-826, (2000).

[14] Ho, Y. S. and G. McKay; "Competitive sorption of copper and nickel ions from aqueous solution using peat", AdsorptionJournal of the International Adsorption Society, Res. 5(4), pp.409-417, (1999).

[15] S., Baup, C., Jaffre, D., Wolbert, and A., Laplanche; "Adsorption of pesticides onto granulated activated carbon: determination of surface diffusivities using simple batch experiments", Adsorption, Res. 6(3), pp. 219-228, (2000).

[16] R. E., Trevbal; "Mass-Transfer Operations", $3^{\text {rd }}$ edition, McGraw Hill, (1981).

\section{Biography}

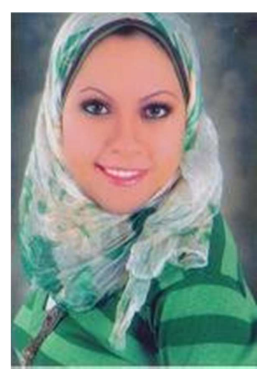

Amany A. Mahmoud is currently working as a senior chemical engineer at Comibassal International Controllers at the environmental section of the research and consulting sector. She is a holder of MSc of science in chemical engineering in "Removal of Heavy Metals from Liquid Wastes" at the Chemical Engineering Department, Faculty of Engineering, Alexandria University, Alexandria, Egypt. Her main research interest is in; treatment of liquid wastes effluent by reducing heavy metals (i.e $\mathrm{Cu}$ (II)) concentration to the allowable limit by using adsorption technique where the modified clay (bentonite) worked as an adsorbent. 